\title{
To pleat or not to pleat...is that the question?
}

\author{
Thomas G. Gleason, MD
}

\footnotetext{
From the Division of Cardiac Surgery, Department of Cardiothoracic Surgery, University of Pittsburgh School of Medicine, Pittsburgh, Pa.

Disclosures: Author has nothing to disclose with regard to commercial support.

Received for publication Nov 7, 2016; accepted for publication Nov 8, 2016.

Address for reprints: Thomas G. Gleason, MD, Division of Cardiac Surgery, Department of Cardiothoracic Surgery, University of Pittsburgh School of Medicine, 5200 Centre Ave, Suite 715, Pittsburgh, PA 15232 (E-mail: gleasontg@upmc.edu).

J Thorac Cardiovasc Surg 2017;153:239-40

$0022-5223 / \$ 36.00$

Copyright (C) 2016 Published by Elsevier Inc. on behalf of The American Association for Thoracic Surgery http://dx.doi.org/10.1016/j.jtcvs.2016.11.022
}

In this issue of the Journal, David and colleagues ${ }^{1}$ of Toronto present the latest update of the longest consecutive series of aortic valve reimplantations since its original description in $1992^{2}$ - a contribution that has been one of the most impactful advances in surgical technique in this era (Figure 1). Their series has been periodically presented in various formats during the last 25 years, and this study specifically highlights longer term echocardiographic and clinical follow-up than previous reports. Once again, they demonstrate their outstanding operative results with short ischemic times, a $1.2 \%$ operative mortality, a $9.6 \%$ in-hospital reoperation rate (mostly for bleeding), a $1.5 \%$ pacemaker rate, and no in-hospital permanent strokes. These results are likely attributable to both the distinct skill of these surgeons and the clinical characteristics of the patients treated (a great majority of patients were male [78\%], young $(80 \%<60$ years], and healthy $[61 \%$ in New York Heart Association functional class I and 25\% in functional class II]). Approximately 50\% of patients had none or mild aortic regurgitation preoperatively, and $63 \%$ had root diameters smaller than $55 \mathrm{~mm}$.

What is perhaps most impressive is their low incidence of aortic regurgitation on echocardiographic follow-up, albeit with some limitations of the data set. Laudably, only 11 of 333 patients had development of moderate to severe (3-4+) aortic regurgitation during a mean clinical follow-up of 10.3 years, with the latest echocardiograms being obtained within 2 years of data set closure for all but 6 patients. It should be noted, however, that only 129 patients $(39 \%)$ have made it to 10 -year follow-up, and $33 \%$ of patients who have made it to 5 years have mild or greater aortic regurgitation. It will be interesting to see how many of these patients have progression to worse aortic regurgitation with time. An additional limitation is that only half of the follow-up echocardiograms were performed by the study site's echocardiographic laboratory, and it is not clear whether all the off-site echocardiograms were adjudicated directly by the study investigators.

The most intriguing aspect of this report is the Toronto group's paradigm shift away from attempting to make

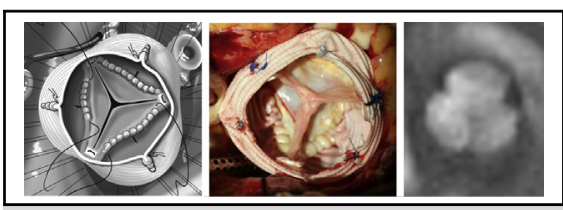

Sketch, photograph, and MRI after aortic valve reimplantation with creation of neosinuses.

Central Message

The value of neosinus creation with reimplantation of the aortic valve: is it futile to continue to attempt to recreate that which we see in nature?

See Article page 232.

neosinuses to accommodate the reimplanted aortic valve. The importance of the sinuses of Valsalva has been recognized for more than 500 years. In fact, the eponym attached to the aortic sinuses, which is based on Antonio Maria Valsalva's descriptions of the sinuses (published posthumously in 1740 by his student, Giovanni Battista Morgagni $^{3}$ ), is perhaps misguided and instead should have gone to Leonardo da Vinci, who described the aortic sinuses and postulated their importance more than 225 years before Valsalva. ${ }^{4,5}$ Since da Vinci's novel discoveries, many others have further corroborated his suspicions. Bellhouse and Reid $^{6}$ and others ${ }^{7}$ have, for example, demonstrated the importance of the eddy currents and reversal of blood flow imparted by the sinuses in facilitating aortic valve closure before the terminal point of systole and in reducing stress on the cusps. In contradistinction, valve cusp stress has been shown to be increased by $173 \%$ when cusps are placed in a cylindrical graft versus within a normal aortic root. ${ }^{8}$ Alternatively, and in addition to the work of Oechtering and colleagues that David and colleagues ${ }^{1}$ highlight, others have shown that creation of graft neosinuses can impart blood flow patterns across the valve and within the root that approach normal flow characteristics. ${ }^{9,10}$ David and colleagues ${ }^{1}$ explain that the reversion to the use of a cylindrical graft without neosinus creation is based on their finding of an apparent association of neosinus creation with the development of moderate to severe aortic regurgitation. This association was determined by a small number of events and by univariate analysis showing a hazard ratio of 1.87 (confidence interval, 1.02-3.42) but not by multivariate analysis. In addition to the small number of events, these two strategies (cylindrical graft with or without neosinuses) were not compared prospectively, nor was there any attempt retrospectively to 

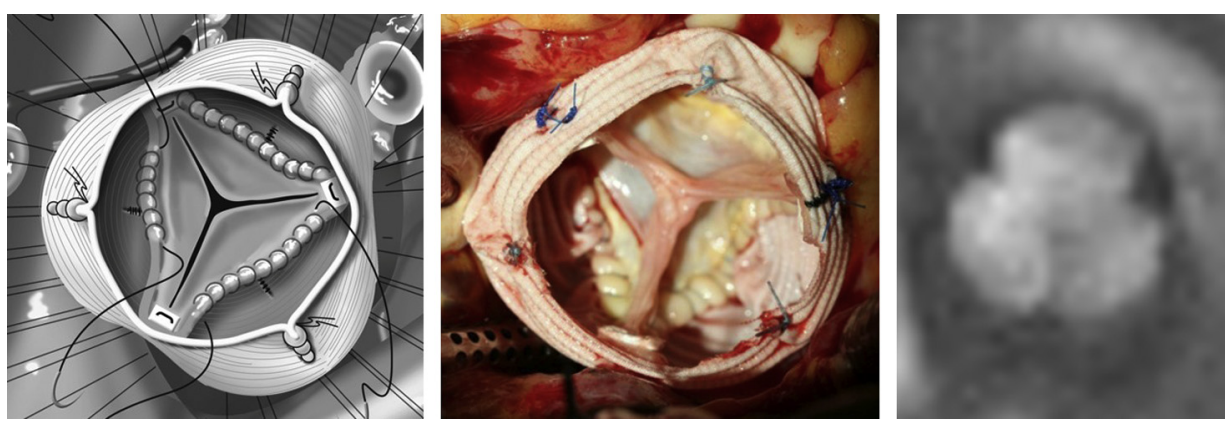

FIGURE 1. Sketch, photograph, and magnetic resonance imaging after aortic valve reimplantation with creation of neosinuses.

match patients by clinical or valvular characteristics and then analyze-again, an impossibility because of the small number of events. In reality, there are no prospective, randomized data available comparing any of the reimplantation techniques that have been described, and a wide variability of techniques used persists across the landscape. Many groups, including my own, use an approach of tailoring neosinuses with a cylindrical graft (ie, not a prefabricated spherical graft), and this approach has yielded results at least at the midterm that are equally favorable as the Toronto group's as seen at their midterm. $^{11,12}$ When our collective experience and follow-up data accumulation stretch robustly beyond 10 and 15 years, we will likely be better equipped to demonstrate the relative value of creating neosinuses. At this point, at least on the basis of well-controlled laboratory study, finite-element analyses, and clinical 4-dimensional flow interrogatories, it is seemingly without question that the sinuses of Valsalva (or da Vinci) are distinctly important to valve function, cusp stress mitigation, and consequent valve durability, and thus it seems prudent to continue to strive to design techniques and materials that better mimic that which we clearly observe in nature-understanding that we have a long way to go to reach that goal.

\section{References}

1. David TE, David CM, Feindel CM, Manlhiot C. Reimplantation of the aortic valve at 20 years. J Thorac Cardiovasc Surg. 2017;153:232-8.

2. David TE, Feindel CM. An aortic valve-sparing operation for patients with aortic incompetence and aneurysm of the ascending aorta. J Thorac Cardiovasc Surg. 1992;103:617-21; discussion 622.

3. Valsalva AM. Arteriae magnae sinus. Valsalva AM. In: Morgagni GB, ed. Opera, 1. Venice: Pitteri; 1740.

4. Keele KD, Roberts J. Leonardo da Vinci: anatomical drawings from the Royal Library, Windsor Castle. New York: Metropolitan Museum of Art; 1983.

5. da Vinci L. The aortic valve (c 1512-1513, Vinci 1452-Amboise 1519). RCIN 919082.

6. Bellhouse BJ, Reid KG. Fluid mechanics of the aortic valve. Br Heart J. 1969;31:391.

7. Robicsek F. Leonardo da Vinci and the sinuses of Valsalva. Ann Thorac Surg. 1991;52:328-35.

8. Grande-Allen KJ, Cochran RP, Reinhall PG, Kunzelman KS. Finite-element analysis of aortic valve-sparing: influence of graft shape and stiffness. IEEE Trans Biomed Eng. 2001;48:647-59.

9. Liu X, Weale P, Reiter G, Kino A, Dill K, Gleason T, et al. Breathhold time-resolved three-directional MR velocity mapping of aortic flow in patients after aortic valve-sparing surgery. J Magn Reson Imaging. 2009;29:569-75.

10. Schoenhoff FS, Loupatatzis C, Immer FF, Stoupis C, Carrel TP, Eckstein FS. The role of the sinuses of Valsalva in aortic root flow dynamics and aortic root surgery: evaluation by magnetic resonance imaging. J Heart Valve Dis. 2009;18: $380-5$.

11. Leontyev S, Trommer C, Subramanian S, Lehmann S, Dmitrieva Y, Misfeld M, et al. The outcome after aortic valve-sparing (David) operation in 179 patients: a single-centre experience. Eur J Cardiothorac Surg. 2012;42:261-6; discussion 266-7.

12. Stephens EH, Liang DH, Kvitting JP, Kari FA, Fischbein MP, Mitchell RS, et al. Incidence and progression of mild aortic regurgitation after Tirone David reimplantation valve-sparing aortic root replacement. J Thorac Cardiovasc Surg. 2014;147:169-77. 178.e1-3. 